\title{
Critical appraisal and selection of data collection instruments: A step-by-step guide
}

\author{
Kathleen N. Dunemn , Carol J. Roehrs, Vicki L. Wilson \\ School of Nursing, University of Northern Colorado, Greeley, CO, United States
}

Received: August 29, 2016

Accepted: October 26, 2016

Online Published: November 1, 2016

DOI: $10.5430 /$ jnep.v7n3p77

URL: http://dx.doi.org/10.5430/jnep.v7n3p77

\begin{abstract}
It is essential that nurse researchers use the most precise and valid data collection instruments available to obtain trustworthy data when conducting research in education and practice. Today, there is a vast selection of existing quantitative data collection instruments from which to choose. Existing instruments can be located through reports of their use in the literature and at conferences, through internet searches and by word of mouth. Once the nurse researcher locates a potential data collection instrument for a given study, the instrument must be systematically appraised for use in that study. This article introduces a comprehensive Step-by-Step Guide that will enable users to quickly and thoughtfully appraise quantitative measurement instruments. The results from the use of this critical appraisal guide will assist researchers to objectively discuss, compare and make informed decisions before adopting a specific data collection instrument for use in a research study. The underlying principles of the Step-by-Step Guide for the Critical Appraisal and Selection of Data Collection Instruments are based on the tenets of measurement theory, literature, and experience of the authors in education and practice research.
\end{abstract}

Key Words: Data collection, Data collection instrument, Selection, Critical appraisal guide

\section{INTRODUCTION}

In the conduct of quantitative research in the areas of education and practice, nurse researchers examine a wide variety of phenomena, requiring an extensive array of quantitative data collection instruments. Quantitative measurement methods are those that assess data or information that can be measured with numbers such as height and weight. The common quantitative measurement approaches used in nursing education and practice research include physiological measures, observations, interviews, questionnaires, and scales. ${ }^{[1-3]}$ Over the last three decades, due to the lack of adequate reliable data collection instruments, healthcare and education researchers have made it a priority to develop and publish quality instruments to measure phenomena of interest. As a result, the number of data collection instruments available has increased exponentially. ${ }^{[2,3]}$ Choosing the best and most appropriate data collection instrument to capture the phenomena of interest is a key and essential step in the research proposal development process. ${ }^{[4,5]}$

Each data collection tool selected should undergo a comprehensive critical appraisal to assess not only the characteristics of reliability and validity, but to also assess the congruence of the measurement method with the research purpose, question(s), hypotheses, design, study population, study setting, conceptual and operational definitions of the planned study variables and the over-all measurement plans. Careful assessment of the subject matter alignment, measurement capabilities, and psychometrics of a data collection instrument

\footnotetext{
*Correspondence: Kathleen N. Dunemn; Email: Kathleen.dunemn@ unco.edu; Address: School of Nursing, University of Northern Colorado, Greeley, CO, United States.
}

Published by Sciedu Press 
are critical tasks for researchers during the research proposal development stages. ${ }^{[3,4]}$

Many journal articles and book chapters that focus on the critical appraisal of research reports exist, however there is a paucity of information available to guide researchers on how to critically appraise and specifically select data collection instruments. Thus, an organized step-by-step approach to guide the critical appraisal and selection of data collection instruments could not be located. Without a step-by-step comprehensive guide, students and new researchers are left to use incomplete appraisal guides when searching out, evaluating and selecting quantitative measurement instruments. The following is a description of the Step-By-Step Guide for the Critical Appraisal and Selection of Data Collection Instruments. The Guide was developed to assist nursing education and practice researchers as they journey through the steps of locating and selecting the most appropriate data collection instrument for a proposed study.

\section{STEP-BY STEP GUIDE}

The Step-by-Step Guide for the Critical Appraisal and Selection of Data Collection Instruments was developed by the authors based on the tenets of the scientific method, measurement theory, available literature, and the authors' experiences in nursing education and practice research. The Guide consists of four interconnected steps. These steps are: Step I. Conceptualize the Proposed Quantitative Research Project; Step II. Find an Existing Measurement Instrument for the Proposed Study; Step III. Critically Assess the Proposed Measurement Instrument; and Step IV. Select or Non-Select the Instrument for the Proposed Study. Each of the four steps are described below. The step elements and key questions to guide the researcher's over-all critical appraisal of a data collection instrument are included in a table describing each step. Although the steps for the Step-by-Step Guide are presented sequentially, the process of identifying and critically assessing an appropriate data collection instrument for a given study is seen as flexible, with iterative work likely among and within the steps. The step elements and questions can be considered comprehensive. However only those key elements and questions based on the best evidence available and the experiences of the authors were selected to be included in the Step-By-Step Guide for the Critical Appraisal and Selection of Data Collection Instruments.

\section{Step I: Conceptualize the proposed quantitative re- search project}

Without knowledge of the foundational elements of a proposed study, researchers would have great difficulty locating and selecting an appropriate existing instrument to evaluate for potential use. ${ }^{[3,4]}$ Step I begins with the researcher de78 scribing and discussing each of the basic elements of the proposed quantitative research project. The basic foundational elements include the study problem, review of the relevant literature, proposed design and methods; research objectives, questions and/or hypotheses; and the proposed study variables and their measurement. ${ }^{[4]}$ Questions and statement prompts have been developed to assist the researcher describe and discuss each of the key foundational elements as they relate to a proposed quantitative study (see Table 1).

Before moving on to Step II, it is suggested that the researcher summarize their responses to Step I elements and questions by developing an initial draft abstract for the proposed study. This abstract should not only include narratives from each of the foundational elements, listed in Step I but also include a measurement plan. This measurement plan should include not only what variables the researcher plans to measure but what the proposed measurement approaches are (e.g., physiological, questionnaire, interview and/or observation guide, scale, etc) ${ }^{[3]}$

\section{Step II: Find an existing instrument for the proposed study}

Once the key elements of the proposed study have been conceptualized and one or more proposed measurement approaches determined (e.g., physiological, questionnaire etc) the next step is for the researcher to seek out and locate potential measurement instruments to critically evaluate for use in their study. Therefore the purpose of Step II is to locate an existing instrument that may align with the key elements of the proposed study identified and summarized in Step I.

To locate existing measurement instruments one can begin by: 1) searching computerized databases such as Medline or CINAHL; 2) searching journals that are devoted specifically to measurement, e.g., Journal of Nursing Measurement; 3) identifying publications in which relevant instruments are used and then using citation indices to locate other publications that used them to access the computer database, the Health and Psychological Instruments Online (HAPI) (this database can be searched for instruments that measure a particular concept or for information on a particular instrument); 4) accessing the Rand Health website (http: //www.rand.org/health/surveys_tools.html) - this website lists many surveys (available without charge) that would be of interest to nurse researchers; 5) reviewing one or more of the many reference books that contain published measurement instruments, for example Measuring Health, A Guide to Rating Scales and Questionnaires ${ }^{[10]}$ and Instruments for Clinical Health-Care Research 3rd Edition; ${ }^{[11]} 6$ ) reviewing Dissertation Abstracts online; and 7) networking and communicating by word-of-mouth with other researchers. $^{[1,3]}$

ISSN 1925-4040 E-ISSN 1925-4059 
Table 1. Step I: Conceptualize the proposed quantitative research project

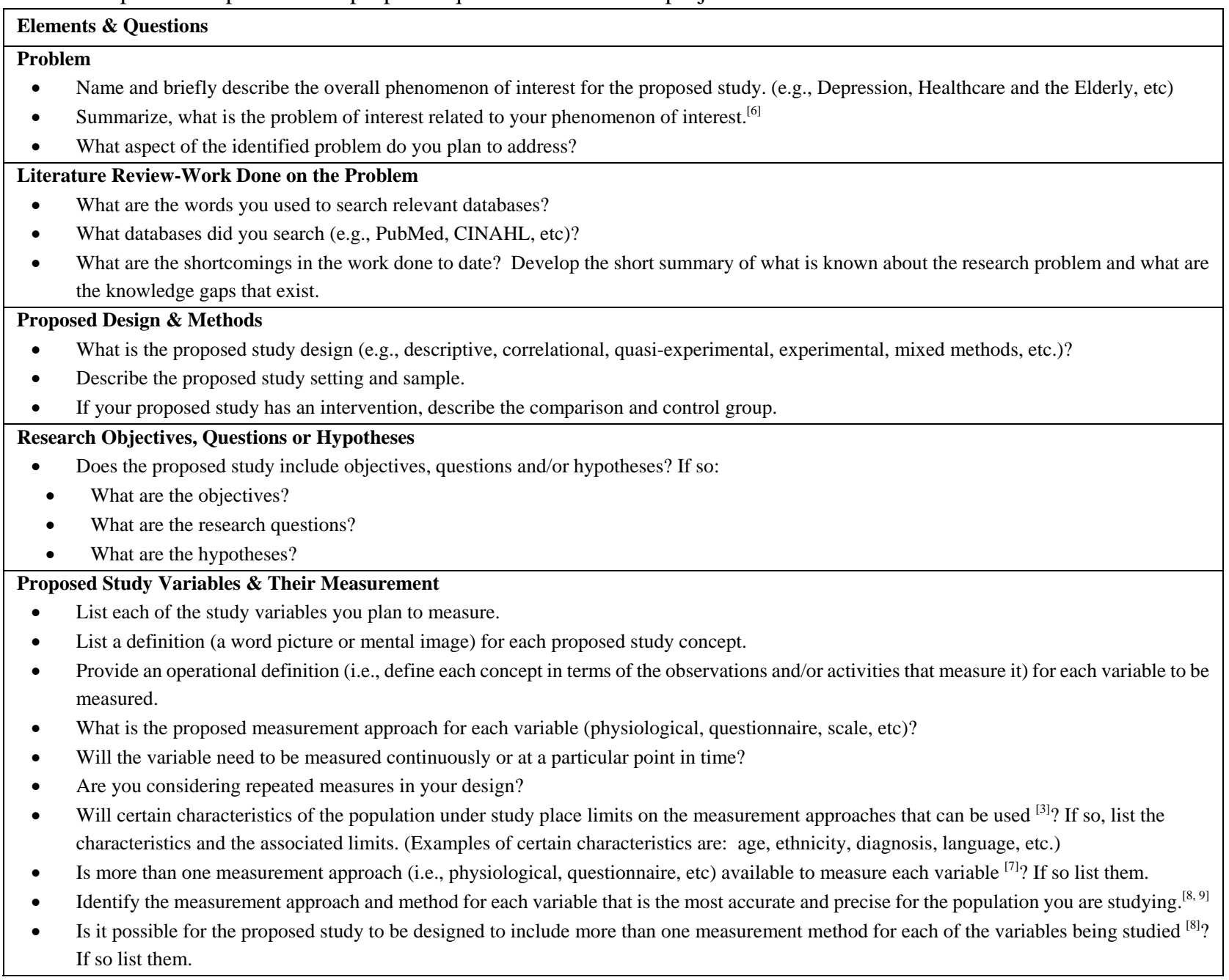

Table 2. Step II. Finding an existing instrument for the proposed study

\begin{tabular}{l}
\hline Elements \& Questions \\
\hline Identify an Instrument \\
- What is the name of the selected instrument? \\
- What is the measurement approach of the instrument (i.e., physiological, questionnaire, etc)? \\
- $\quad$ What variable(s) does the proposed instrument measure? \\
- What sources, databases etc did you search to locate this instrument? (Describe the journey you took to find this instrument). \\
- What is the citation or other needed information for locating this instrument (for all but physiological measurement)? \\
- $\quad$ Why did you select this instrument? \\
Physiological Measurement Approaches \\
- instrument is necessary to be able to complete Steps III-IV of this guide. \\
- $\quad$ Where is this instrument located? \\
- What are the steps to obtain this device for use in your study? \\
- Of note, either a picture with a full written description of the instrument or access to the instrument is necessary to be able to \\
complete Steps III \& IV of this guide.
\end{tabular}


Table 3. Step III. Critical assessment of the proposed measurement instrument

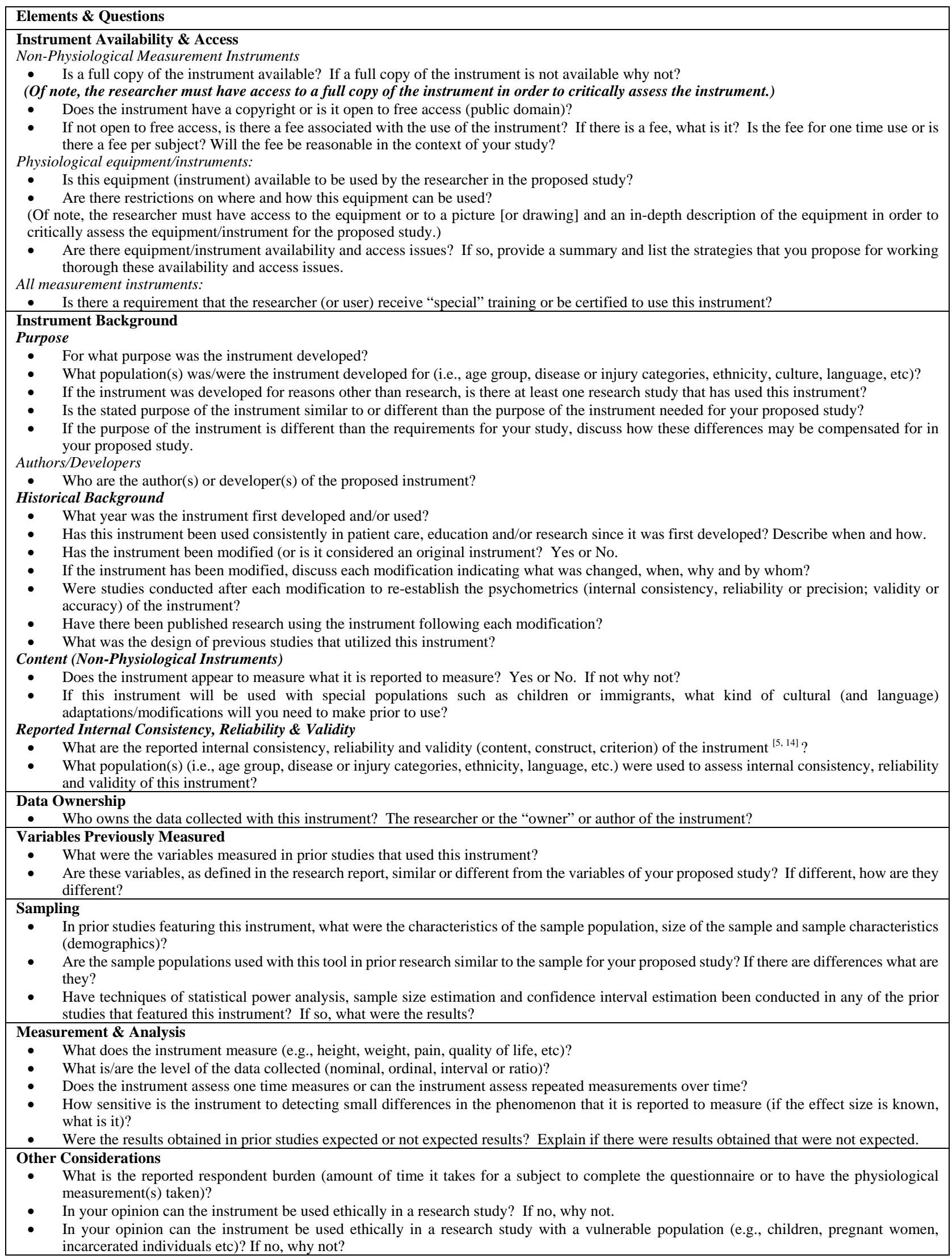


Once a measurement instrument for a proposed study has been located, the next step is for the researcher to document the basic information about the instrument such as the name of the instrument and where the instrument can be located. Table 2 shows the elements and their questions to guide the discussion for Step II.

Prior to beginning Step III, it is suggested that the researcher develop a summary of their responses to Step II elements. The summary of Step II should then be added to the draft abstract for the proposed study developed in Step I. The combined draft abstract and Step II summary will form the foundation for Step III of this guide, critical assessment of the proposed measurement instrument.

\section{Step III: Critical assessment of the proposed measure- ment instrument}

Once an instrument has been located and before a decision can be made about the selection of the instrument for use in a proposed study, the instrument must be critically assessed. The purpose of this critical assessment process is to determine the strengths and weaknesses of the selected data collection instrument and to ensure that the make-up of the instrument aligns with the needs of the proposed study. ${ }^{[5,12,13]}$ Thus, the critical assessment of this potential research instrument must occur within the backdrop of the proposed study articulated in Step I.
To begin, instrument availability and access must be explored followed by a discussion of the instrument background, data ownership, variables previous measured, sampling, measurement and analysis, and other considerations. To complete Step III for non-physiological instruments the researcher must have access to a copy of the instrument. If the instrument collects physiological data, then the researcher must have access to the equipment or to a picture (or drawing) and an in-depth description of the equipment (see Table 3 ).

Before moving forward to Step IV, the researcher should highlight their concerns about the use of the instrument in their proposed study and summarize their responses to each section in Step III. This synopsis should be added to the draft abstract for the proposed study developed in Step I and the summary from Step II. That is the information gathered in Steps I-III which is critical to address the elements and questions in Step IV. The decision to select or non-select the proposed data collection instrument for the study of interest will made in Step IV based on Steps I-III.

\section{Step IV: Decision to select or non-select the data collec- tion instrument for the study of interest \\ Step IV summarizes the information gathered and assessed during Steps I-III and assists the researcher with justifying and making an informed decision to select or non-select the data collection instrument for use in their proposed study. Table 4 guides the researcher through this step.}

Table 4. Decision to select or non-select the data collection instrument for the study of interest

\begin{tabular}{|c|}
\hline Elements \& Questions \\
\hline $\begin{array}{l}\text { Instrument Strengths } \\
\text { - In your opinion, what are the strengths of the measurement instrument? (Strengths would be reasons why you should select the } \\
\text { data collection instrument for your study of interest) }\end{array}$ \\
\hline $\begin{array}{l}\text { Instrument Weaknesses } \\
\text { - What are the weaknesses of the measurement instrument? (Weaknesses would be reasons why you would not select the } \\
\text { instrument for your study of interest) }\end{array}$ \\
\hline $\begin{array}{l}\text { Do you plan to use the instrument in the proposed study? } \\
\text { - If yes, why, what is your rationale, be specific? } \\
\text { - If no, why not? }\end{array}$ \\
\hline $\begin{array}{l}\text { If you do not plan to use this instrument what are your plans for locating another instrument? } \\
\text { Would you refine your search for a new instrument based on the findings from this search and critical assessment? }\end{array}$ \\
\hline $\begin{array}{l}\text { Do you plan to modify this instrument for the proposed study? } \\
\text { - If no, why not? } \\
\text { - If yes, what would be the suggested modifications? In your discussion provide a justification for each of the modifications. } \\
\text { - If you modify the instrument are you prepared to conduct a pilot study of the psychometric properties of the modified } \\
\text { instrument prior to use in the proposed study? } \\
\text { - If no, why not? }\end{array}$ \\
\hline
\end{tabular}




\section{Conclusions}

It is essential that nurse researchers use the most precise and valid measurement instruments available to obtain trustworthy data when conducting research in education and practice. Prior to adopting a data collection instrument, researchers are called upon to critically examine and evaluate all of the characteristics and dimensions of the instrument. The StepBy-Step Guide for the Critical Appraisal and Selection of Data Collection Instruments prompts the researcher to collect pertinent in-depth information about the data collection instrument, critically assess and summarize the information gathered, and make an informed decision to select or not select the measurement instrument for a proposed study. If the researcher decides to modify an existing instrument, the information gathered by the Step-By-Step Guide provides a foundation for the justification for the modification as well as areas of suggested modification.

\section{CONFlicts OF InTEREST Disclosure}

The authors declare that they have no competing interests.

\section{REFERENCES}

[1] Grove SK, Burns N, Gray JR. The Practice of Nursing Research Appraisal, Synthesis, and Generation of Evidence (7th ed). St. Louis, MO: Elsevier Publishers; 2013.

[2] Tappen R. Advanced Nursing Research: From Theory to Practice (2nd ed). Burlington, MA: Jones \& Bartlett Learning; 2016.

[3] Waltz C, Strickland OL, Lenz E. Measurement in Nursing and Health Research (4th ed.). New York, NY: Springer Publishing Company; 2010 .

[4] Funk SG, Tornquist EM. Writing Winning Proposals For Nurses and Health Care Professionals. New York, NY: Springer Publishing Company; 2016.

[5] Scholtes VA, Terwee CB, Poolman RW. What Makes a Measurement Instrument Valid and Reliable? Injury, International Journal of Care for the Injured. 2011; 42: 236-240. PMid:21145544 http://dx.doi.org/10.1016/j.injury.2010.11.042

[6] Davis SL, Morrow AK. Creating usable assessment tools: A step-by-step guide to instrument design. 2013. Available from: http: //www.docdatabase.net/more-creating-usable-assessm ent-tools-a-step-by-step-guide-to--1141299.html

[7] Stone KS, Frazier SK. Measurement of Physiological Variables Using Biomedical Instrumentation. In C. F. Waltz, O. L. Strickland \& E. R. Lenz (Eds). Measurement in Nursing and Health Research (4th ed., pp. 335-370). New York, NY: Springer Publishing Company; 2010. PMid:20579905
[8] Fawcett J, Garity J. Evaluating Research for Evidence-Based Nursing Practice. Philadelphia, PA: F. A. Davis; 2009.

[9] Ryan-Wenger NA. Evaluation of measurement precision, accuracy, and error in biophysical data for clinical research and practice. In C. F. Waltz, O. L. Strickland \& E. R. Lenz (Eds). Measurement in Nursing and Health Research (4th ed., pp. 371-383). New York, NY: Springer Publishing Company; 2010.

[10] McDowell I. Measuring Health: A Guide to Rating Scales and Questionnaires. New York, NY: Oxford University Press; 2006. http://dx.doi.org/10.1093/acprof : oso/9780195165678.001.0001

[11] Frank-Stromborg M, Olsen SJ. Instruments For Clinical Health-Care Research (3rd ed). Sudburn, MA: Jones and Bartlett Publishers, Inc.; 2004

[12] Lohr KN, Aaronson NK, Alonso J, et al. Evaluating Quality-ofLife and Health Status Instruments: Development of Scientific Review Criteria. Clinical Therapeutics. 1996; 18(5): 979-992. http: //dx.doi.org/10.1016/S0149-2918(96)80054-3

[13] Terwee CB, Bot SDM, deBoer MR, et al. Quality Criteria Were Proposed for Measurement Properties of Health Status Questionnaires. Journal of Clinical Epidemiology. 2007; 60: 34-42. PMid:17161752 http://dx.doi.org/10.1016/j.jclinepi.2006.03.012

[14] Polit DF, Beck CT. The Content Validity Index: Are You Sure You Know What's Being Reported? Critique and Recommendations. Research in Nursing \& Health. 2006; 29: 489-497. PMid:16977646 http://dx.doi.org/10.1002/nur. 20147 